\title{
Development of an Electrochemical Sensor for Determination of Ligustrazine Based on Nitrogen-Doped Multi-Walled Carbon Nanotube
}

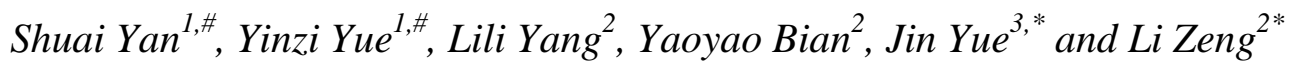 \\ ${ }^{1}$ Suzhou Hospital of Traditional Chinese Medicine, Suzhou, Jiangsu 215009, China \\ ${ }^{2}$ Nanjing University of Chinese Medicine, Nanjing, Jiangsu, 210023,China \\ ${ }^{3}$ Yancheng Hospital of Traditional Chinese Medicine, yancheng, Jiangsu 224001, China \\ \#These authors contributed equally to this work. \\ *E-mail: zengbingli@163.com
}

doi: $10.20964 / 2017.09 .55$

Received: 16 May 2017 / Accepted: 12 July 2017 / Published: 13 August 2017

In this work, $\beta$-cyclodextrin and nitrogen-doped multi-walled carbon nanotube (NCNT) were directly incorporated to graphite powder, and an electrochemical treatment was implemented for the fabrication of a new sensor. The characteristics of the as-prepared electrode were studied using cyclic voltammetry (CV) measurement. Due to the synergic effects of $\beta$-cyclodextrin and NCNT, the response of our developed sensor for ligustrazine was more significant than that of other electrodes. Our developed sensor exhibited excellent performance in the quantitative determination of ligustrazine in Ligusticum wallichii.

Keywords: Ligustrazine; $\beta$-cyclodextrin; Nitrogen-doped multi-walled carbon nanotube; Electrochemical determination; Ligusticum wallichii

\section{FULL TEXT}

(C) 2017 The Authors. Published by ESG (www.electrochemsci.org). This article is an open access article distributed under the terms and conditions of the Creative Commons Attribution license (http://creativecommons.org/licenses/by/4.0/). 